\title{
EFFECTS OF LONG-TERM ALENDRONATE TREATMENT ON BONE MINERALISATION, RESORPTION PARAMETERS AND BIOMECHANICS OF SINGLE HUMAN VERTEBRAL TRABECULAE
}

\author{
M. Krause ${ }^{1,2}$, M. Soltau ${ }^{1}$, E.A. Zimmermann ${ }^{1}$, M. Hahn ${ }^{1}$, J. Kornet ${ }^{1,3}$, A. Hapfelmeier ${ }^{4}$, S. Breer ${ }^{1}$, M. Morlock ${ }^{3}$, \\ B. Wulff ${ }^{5}$, K. Püschel ${ }^{5}$, C-C. Glueer ${ }^{6}$, M. Amling ${ }^{1}$ and B Busse ${ }^{1, *}$
}
${ }^{1}$ Department of Osteology and Biomechanics, University Medical Center Hamburg-Eppendorf, Hamburg, Germany ${ }^{2}$ Department of Trauma and Reconstructive Surgery, Asklepios Clinic St. Georg, Hamburg, Germany ${ }^{3}$ Institute of Biomechanics, TUHH Hamburg University of Technology, Hamburg, Germany
${ }^{4}$ Institute of Medical Statistics and Epidemiology, Technical University, Munich, Germany ${ }^{5}$ Department of Legal Medicine, University Medical Center Hamburg-Eppendorf, Hamburg, Germany ${ }^{6}$ Section Biomedical Imaging, Department of Diagnostic Radiology, University Hospital Schleswig-Holstein, Campus Kiel, Kiel, Germany

\begin{abstract}
Due to their well-established fracture risk reduction, bisphosphonates are the most frequently used therapeutic agent to treat osteoporosis. Bisphosphonates reduce fracture risk by suppressing bone resorption, but the lower bone turnover could have a negative impact on bone quality at the tissue level. Here, we directly assess the structural and mechanical characteristics of cancellous bone from the lumbar vertebrae (L5) in non-treated osteoporotic controls $(n=21)$, mid-term alendronate-treated osteoporotic patients $(n=6)$, and long-term alendronate-treated osteoporotic patients $(n=7)$. The strength and toughness of single trabeculae were evaluated, while the structure was characterised through measurements of microdamage accumulation, mineralisation distribution, and histological indices. The alendronate-treated cases had a reduced eroded surface $(\mathrm{ES} / \mathrm{BS}, p<0.001)$ and a higher bone mineralisation in comparison to non-treated controls $(p=0.037)$, which is indicative of low turnover associated with treatment. However, the amount of microdamage and the mechanical properties were similar among the control and treatment groups. As the tissue mineral density (TMD) increased significantly with alendronate treatment compared to nontreated osteoporotic controls, the reduction in resorption cavities could counterbalance the higher TMD allowing the alendronate-treated bone to maintain its mechanical properties and resist microdamage accumulation. A multivariate analysis of the possible predictors supports the theory that multiple factors (e.g., body mass index, TMD, and ES/BS) can impact the mechanical properties. Our results suggest that long-term alendronate treatment shows no adverse impact on mechanical cancellous bone characteristics.
\end{abstract}

Keywords: Osteoporosis, alendronate, histomorphometry, microcomputed-tomography, mineralisation, microdamage.

*Address for correspondence:

Björn Busse

Department of Osteology and Biomechanics

University Medical Center Hamburg-Eppendorf

Lottestr. 59, 22529 Hamburg, Germany

Telephone Number: +49-40-7410-56373

E-mail: b.busse@uke.uni-hamburg.de
Vertebral fractures are the most common fragility fractures in patients with osteoporosis and potentially lead to adverse effects, such as acute or chronic back pain, disability, and impairment in quality of life (Oleksik et al., 2000; Krause et al., 2012b). Currently, bisphosphonates represent the most frequently used therapeutic agent to prevent osteoclastinduced bone loss, such as in post-menopausal osteoporosis. An average bisphosphonate treatment duration of 3 to 4 years is associated with a significant fracture risk reduction of up to $50 \%$ for vertebral fractures and up to $55 \%$ for non-vertebral fractures (Black et al., 1996; Cummings et al., 1998; Harris et al., 1999); however, bisphosphonate treatment is often continued indefinitely. As the main effect of bisphosphonates is based on a continuous suppression of bone turnover, which could impair the structure and mechanical properties of the remaining bone tissue, there are reservations in the medical community regarding the use of bisphosphonates as a long-term therapy.

Currently, only a few clinical studies analyse the clinical consequences of long-term bisphosphonate therapy in humans (Bone et al., 2004; Black et al., 2006; Black et al., 2012). Two studies have shown that continued bisphosphonate treatment over the average duration of 3-5 years lowers the risk of vertebral fractures and preserves the increased areal bone mineral density (aBMD) compared to patients who discontinue therapy after the average duration (Black et al., 2006; Black et al., 2012). Other than the benefits of a higher aBMD, factors relating to bone quality (e.g., size, geometry, microarchitecture or microdamage accumulation) have not been completely evaluated although they could also explain the fracture risk reduction associated with bisphosphonate treatment (Ammann and Rizzoli, 2003). Some effects of long-term bisphosphonate therapy may be detrimental. For instance, an increase in the average degree of mineralisation due to suppression of bone turnover could lead to microdamage accumulation, resulting in reduced bone strength and toughness (Boivin et al., 2000; Roschger et al., 2001; Nyman et al., 2004). An accumulation of microdamage due to the suppression of bone turnover is well established in animal studies (Mashiba et al., 2000; Mashiba et al., 2001; Allen et al., 2006), while data from human bone are inconsistent (Chapurlat et al., 2007; Stepan et al., 2007).

Nonetheless, even if microdamage increasingly occurs with long-term bisphosphonate therapy, the impact of 
long-term bisphosphonate therapy on mechanical bone tissue characteristics and their clinical importance is largely unknown (Allen and Burr, 2011). In principle, bisphosphonate therapy may result in improved bone characteristics accompanied by changes in Young's modulus (Ding et al., 2003; Day et al., 2004) and reduced toughness (Komatsubara et al., 2003; Allen and Burr, 2007; Wang et al., 2008). While these principles have largely been established through animal models, studies on humans with severely suppressed bone turnover due to long-term bisphosphonate therapy have been more conflicting, indicating both improved (Tjhia et al., 2011) and deteriorated (Bala et al., 2011) mechanical properties in cortical and cancellous bone.

Indeed, inter-individual variations may explain the fracture risk reduction in some patients and the deterioration in mechanical properties of other patients. Specifically, patients with atypical femoral fractures (AFF) have been repeatedly documented after long-term bisphosphonate therapy (Vaishya et al., 2013; Bottai et al., 2014; Zanchetta et al., 2014). A recent study using microindentation found deteriorated bone material properties in patients with both typical and atypical hip fractures in comparison to untreated controls. However, patients with long-term bisphosphonate therapy were not statistically different from untreated controls, which suggests that bisphosphonate treatment itself may not necessarily impair bone material properties (Guerri-Fernandez et al., 2013).

To further investigate the complex effects of long-term bisphosphonate therapy, the aim of the present study was to directly assess the structural and mechanical characteristics of human cancellous bone. As bisphosphonates affect bone tissue properties on different structural levels, the effects of bisphosphonate treatment duration are investigated at the single trabeculae level by quantifying microdamage accumulation, bone turnover activity, bone tissue mineralisation and mechanical properties.

\section{Materials and Methods}

\section{Materials}

In this study, 35 patients were included from the ex vivo "Biomechanically founded individualized osteoporosis assessment and treatment (BioAsset)" study with the goal to elucidate the effects of bisphosphonate treatment on bone by combining imaging and biomechanical techniques (Glüer et al., 2013; Krause et al., 2014; Museyko et al., 2014). Inclusion criteria were females with postmenopausal osteoporosis, which was diagnosed according to the World Health Organization definition, with a lumbar or femoral areal bone mineral density (aBMD) $T$-Score of -2.5 or less assessed by dual x-Ray absorptiometry (DXA). Exclusion criteria included bone cancer, immobility $>1$ year, renal transplantation or renal insufficiency III, strontium or fluoride therapy, specific anti-resorptive medication other than bisphosphonates and bisphosphonate therapy $<1$ year. Informed consent was obtained from the family members after comprehensive information on all related issues. The study was approved by the Ethics Committee of the Hamburg Chamber of Physicians (PV3486). Thirty- five patients matching the inclusion criteria were included. One patient had to be excluded due to lumbar spinal fusion. Therefore, the lumbar spinal column was obtained from 34 patients (median age: 83 years [range: 65 to 90 years]) during autopsy at the Department of Forensic Medicine, University Medical Centre Hamburg-Eppendorf (Fig. 1). All patients were categorised according to bisphosphonate treatment duration prior to death as follows:

- Control group $(n=21)$, females with diagnosed osteoporosis but no documented history of bisphosphonate treatment

- Mid-term bisphosphonate-treated group $(n=6)$, females taking bisphosphonates for a duration of 1-5 years (mean $2.16 \pm 0.99$ years)

- Long-term bisphosphonate-treated group $(n=7)$, females taking bisphosphonates for a duration of 6 years.

The treatment for all patients on bisphosphonate therapy consisted of weekly alendronate.

\section{Preparation of single trabeculae}

To prepare single trabeculae for mechanical testing, the L5 vertebra was dissected along the sagittal direction in three sections (Fig. 1A). The trabeculae were singularised according to methods previously described in detail (Busse et al., 2009). Briefly, the central $5 \mathrm{~mm}$ slice of L5 was soaked in hydrogen peroxide for $8 \mathrm{~h}$ and rinsed with demineralised water to remove soft tissue. According to guidelines established by previous studies (Busse et al., 2009), trabeculae were removed from defined regions within the section. At least 20 single, rod-like trabeculae were harvested from each specimen using a headset magnifier (2.3, Carl Zeiss, Jena, Germany) and a mini scalpel (No. 11, Bahya, Tuttlingen, Germany). To ensure that only intact trabeculae were tested, the structural integrity was examined in a polarised light microscope.

\section{Biomechanical testing}

The strength of single trabeculae from the L5 vertebrae was assessed via three-point bending tests using a materials testing device with a $10 \mathrm{~N}$ force sensor (Z.2.5/TN1S, Zwick/Roell, Ulm, Germany). Prior to the testing procedure (Busse et al., 2009), appropriate trabeculae were identified. Ideally, only trabeculae that are precisely cylindrically shaped should be tested. Therefore, in accordance with previous studies, trabeculae with a maximum ratio of 1:1.3 between minor and major cross-sectional axis were included (Busse et al., 2009). Additionally, the tested trabeculae had a minimum thickness of $90 \mu \mathrm{m}$. All dimensions were determined with a stereomicroscope (SZH-ILLD, Olympus, Osaka, Japan). The specimens were dried to ensure that no adhesion phenomena occurred during the mounting and materials testing process. Each trabecula was placed on the custom-built three-point bending fixture. The fixture's bottom support consists of two pins with a diameter of $1.0 \mathrm{~mm}$ and a span of $600 \mu \mathrm{m}$. The top fixture consisted of a cross-head with a rounded-off tip of radius $0.1 \mathrm{~mm}$ that was positioned half way between the two pins on the lower fixture. The sample was placed on the bottom support's pins and load was applied to the sample via the cross-head at a speed of $2 \mathrm{~mm} / \mathrm{min}$. The 
a

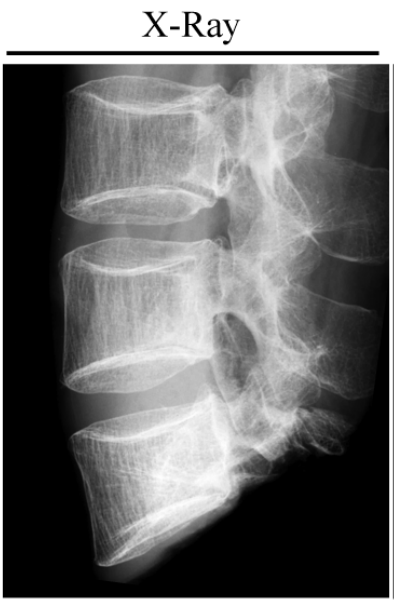

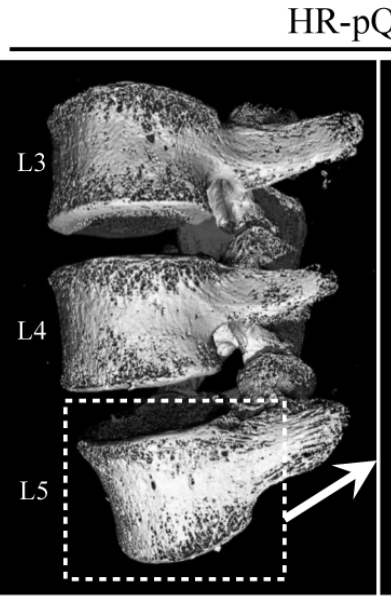

HR-pQCT

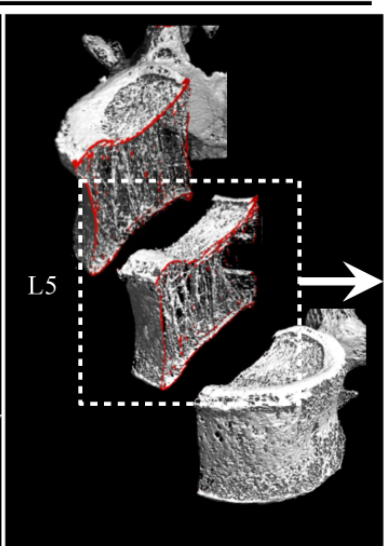

L5

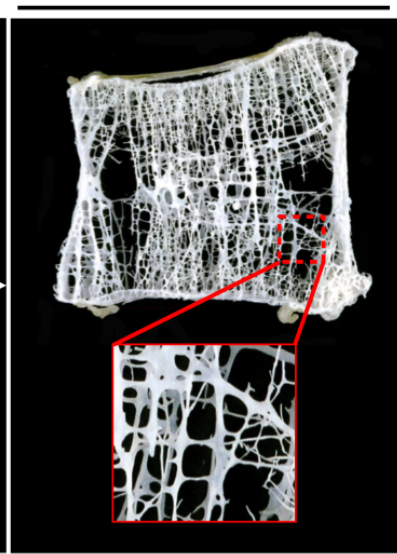

b
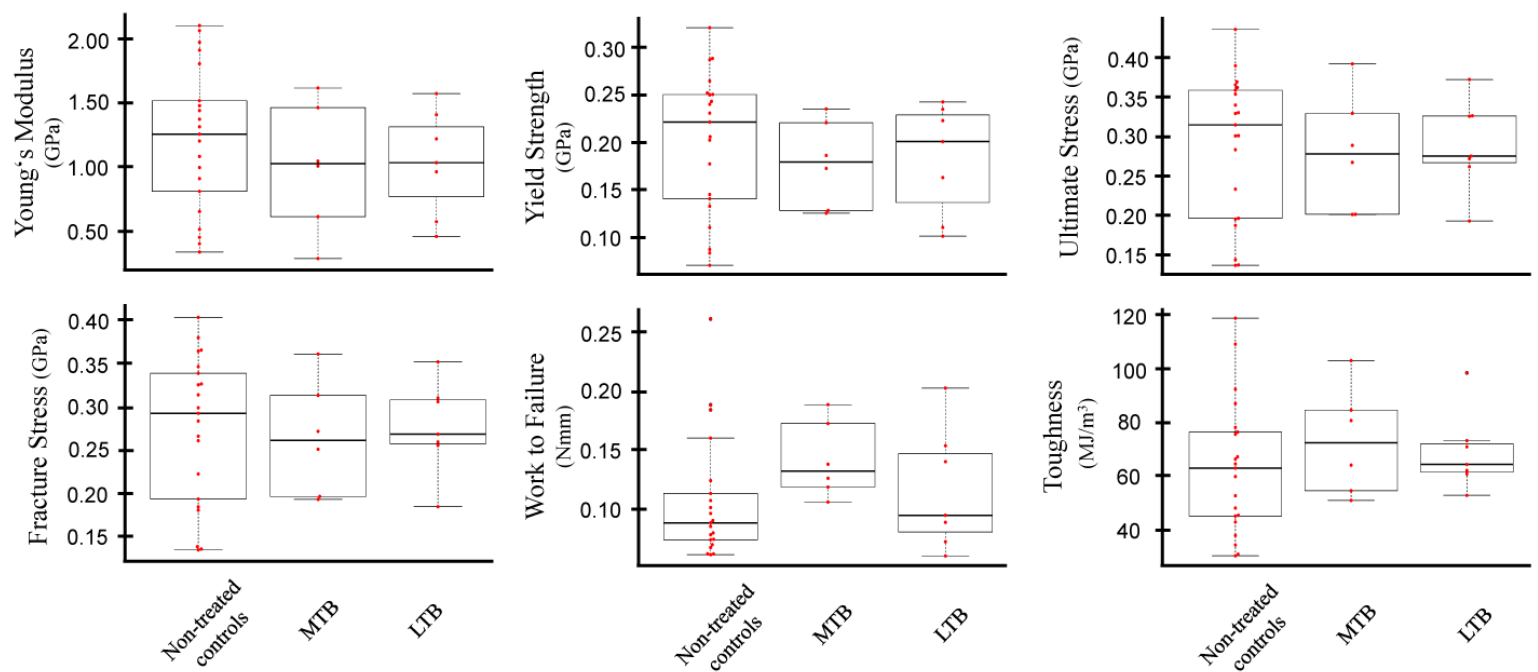

Fig. 1. (A) Procedure for preparation of the lumbar spine. X-ray of the lumbar spine L3-L5. HR-pQCT (high-resolution quantitative computer tomography, SCANCO Medical, Bruettisellen, Switzerland) of the lumbar spine L3-L5 with highlighted vertebra of interest (dotted line). Segmentation of L5 (HR-pQCT for illustration) with macerated L5 highlighting the trabecular network (3x magnification). (B) The mechanical properties measured during mechanical testing. Comparisons were performed by $t$-test and ANOVA or the non-parametric Mann-Whitney U test and KruskalWallis test.

load and displacement data were collected during testing and the bending test ended after fracture of the trabecula. The ultimate load was taken as the highest load achieved during the test and the fracture load was taken as the final load at fracture. The load and displacement curve was normalised by the specimen geometry, such that the Young's modulus $(\mathrm{GPa})$, yield strength $(\mathrm{GPa})$, ultimate stress $(\mathrm{GPa})$ and fracture stress $(\mathrm{GPa})$ could be determined from the stress-strain curve. The work to failure (W, $\mathrm{N} \mathrm{mm}$ ) was measured from the area under the load-displacement curve. Then, the toughness was calculated according to Mashiba et al. (Mashiba et al., 2000) by normalising the work to failure (W, $\mathrm{N} \mathrm{mm}$ ):

$$
\text { Toughness }=0.75 \mathrm{~Wb}^{2} /(0.6 \mathrm{I})
$$

where $b$ is the width of the trabecula. $I$ is the cross-sectional moment of inertia with the assumption of a circular crosssection:

$$
I=(\pi / 4) r^{4}
$$

where $r$ is the radius of the trabecula.

\section{Static 3D-histomorphometry and histological analysis}

The second sagittal section of the L5 vertebrae was used for histological analysis. Prior to further preparation, the vertebral remnants were scanned in a micro-computed tomography $(\mu \mathrm{CT})$ device $(\mu \mathrm{CT} 40$, SCANCO Medical AG, Bruettisellen, Switzerland) with an in vitro scanning protocol (55 kVp, $145 \mu \mathrm{A}, 200 \mathrm{~ms}$ integration time) resulting in an isotropic $10 \mu \mathrm{m}$ voxel size to assess the static $3 \mathrm{D}$ bone histomorphometry. The following histomorphometric parameters were measured according to American Society for Bone and Mineral Research (ASBMR) standards (Dempster et al., 2013): the vertebral BV/TV (bone volume/tissue volume, \%), Tb.Th (trabecular thickness, mm), Tb.N (trabecular number, $/ \mathrm{mm}$ ), Tb.Sp 
(trabecular separation, mm) as well as SMI (structure model index, dimensionless). Additionally, the degree of mineralisation was determined with $\mu \mathrm{CT}$ measuring the bone tissue mineral density (TMD, mg hydroxyapatite [HA] $/ \mathrm{cm}^{3}$ ) (Mulder et al., 2004; Burghardt et al., 2008). After completion of the 3D $\mu \mathrm{CT}$ measurements, the upper half of the specimens was subjected to an undecalcified infiltration process, plastic embedded, and cut into $5 \mu \mathrm{m}$ sections. Then, the bone sections were stained using either the von-Kossa technique, toluidine blue or Goldner trichrome, as previously described (Breer et al., 2012; Krause et al., 2012a). The ratio of osteoid volume per bone volume (OV/BV, \%), osteoid surface per bone surface (OS/ BS, \%) and eroded surface (ES/BS, \%) were assessed using an automated computer-assisted image analysing system (OsteoMeasure, OsteoMetrics, Decatur, GA, USA).

\section{Microdamage assessment}

To evaluate microdamage, sections from the last third of the L5 vertebrae were prepared by bulk staining using calcein (Lee et al., 2000; Aruwajoye et al., 2013). Specimens were put in $0.9 \%$ saline for $4 \mathrm{~h}$ after previous dehydration in alcohol ( $80 \%$ ethanol). Subsequently, the specimens were soaked in calcein $(0.3 \mathrm{~g} / 100 \mathrm{~mL}$ saline $)$ for $2 \mathrm{~h}$ under vacuum $(20 \mathrm{mmHg})$, rinsed with reverse osmosis water for another $10 \mathrm{~min}$ and plastic embedded. Finally, central $5 \mu \mathrm{m}$ sections were obtained. The microdamage assessment was performed in a region of interest (ROI) of at least $5 \mathrm{~mm}^{2}$ using the OsteoMeasure system. Microdamage was defined according to the established criteria by Burr and Stafford (Burr and Stafford, 1990; Lee et al., 2003), including intermediate size, sharp borders with increased fluorescence, deep staining after focus changing and linear shape. ROIs were scanned for the occurrence of microdamage at 100x magnification; when microdamage was detected, the number of cracks (Cr.N) and crack length $(\mathrm{Cr} . \mathrm{Le}, \mu \mathrm{m})$ were measured at 200x magnification. In accordance with previous studies, crack density (Cr. Dn, $\# / \mathrm{mm}^{2}$ ) and crack surface density (Cr.S.Dn, $\mu \mathrm{m} / \mathrm{mm}^{2}$, Cr.N*Cr.Le/BS) were determined (Aruwajoye et al., 2013; Chapurlat et al., 2007). Intra-observer reliability for the detection of microdamage was high (ICC: 0.996 [95\% confidence interval: $0.985,0.999]$ ) with a repeatability coefficient of 0.620 .

\section{Statistics}

Statistical analysis was carried out using $\operatorname{IBM}^{\circledR} \operatorname{SPSS}^{\circledR}$ Statistics 19 and the software package R (The R Foundation for Statistical Computing, Vienna, Austria). The distribution of categorical data is presented by absolute and relative frequencies. Descriptive statistics of continuous, normally and non-normally distributed data are given by mean \pm standard deviation and median (range), respectively. Accordingly, comparisons of two or more groups were performed by $t$-test and analysis of variance (ANOVA) or the non-parametric Mann-Whitney U test and Kruskal-Wallis test. Spearman's correlation coefficient was used to assess the relationships among the TMD, bisphosphonate treatment duration and body mass index (BMI, $\mathrm{kg} / \mathrm{m}^{2}$ ). In a univariate and multivariate analysis (ANCOVA) blind to treatment, possible predictors (age, body mass index, bisphosphonate exposition, TMD, osteoid parameters (OV/BV \& OS/BS), Cr.Le, Cr.Dn and Cr.S.Dn) of the mechanical properties were identified using a stepwise forward variable selection based on Akaike's Information Criterion. All statistical tests were performed in an explorative manner at a $5 \%$ significance level.

\section{Results}

Concerning baseline patient characteristics, parameters such as age and body mass index, which are known to independently influence mechanical properties of bone tissue, were not significantly different among the study groups (Table 1).

\section{Histomorphometry}

The histomorphometric analysis revealed that the overall bone volume (BV/TV) was marginally higher in controls (Table 1) due to the greater number of trabeculae (Tb.N; $p=0.019)$, which were slightly thinner (Tb.Th; Table 1) and significantly farther apart from each other (Tb.Sp; $p=0.017$ ) in controls compared to the alendronate-treated groups. All three groups demonstrated an almost similar SMI with a tendency toward a more rod-like structure (mean: $1.92 \pm 0.36$ ). The amount of non-mineralised bone matrix $(\mathrm{OV} / \mathrm{BV}, \mathrm{OS} / \mathrm{BS})$ was marginally lower in patients with alendronate treatment compared to controls $(\mathrm{OV} /$

Table 1. Patient characteristics and summary of histomorphometric parameters (mean \pm standard deviation and median (range)). Comparisons were performed by $t$-test and ANOVA or the non-parametric MannWhitney U test and Kruskal-Wallis test.

\begin{tabular}{|c|c|c|c|c|c|}
\hline & All & $\begin{array}{c}\text { No } \\
\text { treatment }\end{array}$ & $\begin{array}{c}\text { Mid-term } \\
\text { treatment }\end{array}$ & $\begin{array}{c}\text { Long-term } \\
\text { treatment }\end{array}$ & \multirow{2}{*}{$p$-value } \\
\cline { 2 - 5 } Parameters & $(n=34)$ & $(n=21)$ & $(n=6)$ & $(n=7)$ & 0.305 \\
\hline Age $($ years $)$ & $83(65,90)$ & $84(65,90)$ & $86(75,90)$ & $82(67,86)$ & 0.439 \\
\hline BMI $\left(\mathrm{kg} / \mathrm{m}^{2}\right)$ & $21(16,34)$ & $20(16,31)$ & $22(18,28)$ & $24(17,34)$ & 0.243 \\
\hline BV/TV $(\%)$ & $5.7(3.0,12.1)$ & $6.3(4.0,12.1)$ & $4.6(3.3,7.4)$ & $4.7(3.0,7.7)$ & 0.019 \\
\hline Tb.N $(/ m m)$ & $0.91 \pm 0.15$ & $0.97 \pm 0.15^{\text {a }}$ & $0.81 \pm 0.09$ & $0.82 \pm 0.16$ & 0.500 \\
\hline Tb.Th $(\mu m)$ & $117.3 \pm 20.1$ & $114.2 \pm 20.5$ & $124.1 \pm 24.7$ & $121.1 \pm 14.7$ & 0.017 \\
\hline Tb.Sp $(m m)$ & $1.10 \pm 0.20$ & $1.03 \pm 0.17^{\text {a }}$ & $1.21 \pm 0.13$ & $1.23 \pm 0.25$ & 0.187 \\
\hline SMI & $1.92 \pm 0.36$ & $1.84 \pm 0.32$ & $2.07 \pm 0.33$ & $2.06 \pm 0.43$ & \\
\hline
\end{tabular}

a: $p<0.05$ for controls $v s$. long-term treatment. 
Table 2. Univariate and multivariate analysis of mechanical properties. Univariate and multivariate analysis (ANCOVA) were performed blind to treatment.

\begin{tabular}{|c|c|c|c|c|c|c|c|c|c|c|c|}
\hline \multirow[b]{2}{*}{ Outcome } & \multirow[b]{2}{*}{ Predictor } & \multicolumn{5}{|c|}{ univariate } & \multicolumn{5}{|c|}{ multivariate } \\
\hline & & Intercept & Coefficient & SE & $\mathrm{r}$ & $p$ & Intercept & Coefficient & SE & $\mathrm{R}^{2}$ & $p$ \\
\hline \multirow{7}{*}{$\begin{array}{l}\text { Young's } \\
\text { Modulus }\end{array}$} & Age & -0.152 & 0.016 & 0.013 & 0.217 & 0.218 & & & & & \\
\hline & BMI & 2.078 & -0.042 & 0.018 & -0.382 & 0.026 & 2.062 & -0.051 & 0.018 & 0.238 & 0.007 \\
\hline & TMD & 7.768 & -0.007 & 5.326 & -0.378 & 0.028 & & & & & \\
\hline & $\mathrm{ES} / \mathrm{BS}$ & 1.312 & -0.017 & 0.023 & -0.131 & 0.459 & & & & & \\
\hline & Cr.Le & 1.008 & 0.583 & 0.531 & 0.191 & 0.280 & & 0.960 & 0.497 & & 0.063 \\
\hline & Cr.Dn & 1.078 & 0.015 & 0.042 & 0.063 & 0.723 & & & & & \\
\hline & Cr.S.Dn & 1.067 & 0.066 & 0.072 & 0.159 & 0.369 & & & & & \\
\hline \multirow{7}{*}{$\begin{array}{c}\text { Yield } \\
\text { Strength }\end{array}$} & Age & 0.038 & 0.002 & 0.002 & 0.203 & 0.250 & 0.865 & 0.003 & 0.001 & 0.352 & 0.056 \\
\hline & BMI & 0.250 & -0.003 & 0.002 & -0.184 & 0.297 & & & & & \\
\hline & TMD & 0.997 & -0.001 & 0.0004 & -0.360 & 0.036 & & -0.001 & 0.0004 & & 0.018 \\
\hline & ES/BS & 0.220 & -0.003 & 0.003 & -0.165 & 0.351 & & -0.005 & 0.003 & & 0.067 \\
\hline & Cr.Le & 0.163 & 0.128 & 0.065 & 0.330 & 0.057 & & 0.118 & 0.060 & & 0.059 \\
\hline & Cr.Dn & 0.184 & 0.002 & 0.005 & 0.065 & 0.716 & & & & & \\
\hline & Cr.S.Dn & 0.175 & 0.015 & 0.009 & 0.291 & 0.095 & & & & & \\
\hline \multirow{7}{*}{$\begin{array}{c}\text { Ultimate } \\
\text { Stress }\end{array}$} & Age & 0.160 & 0.002 & 0.002 & 0.140 & 0.429 & 1.005 & 0.003 & 0.002 & 0.278 & 0.165 \\
\hline & BMI & 0.297 & -0.0004 & 0.003 & -0.022 & 0.901 & & & & & \\
\hline & TMD & 1.053 & -0.001 & 0.0005 & -0.282 & 0.107 & & -0.001 & 0.0005 & & 0.059 \\
\hline & ES/BS & 0.336 & -0.005 & 0.004 & -0.238 & 0.176 & & -0.007 & 0.003 & & 0.043 \\
\hline & Cr.Le & 0.259 & 0.130 & 0.080 & 0.275 & 0.115 & & 0.123 & 0.077 & & 0.120 \\
\hline & Cr.Dn & 0.294 & -0.001 & 0.006 & -0.034 & 0.850 & & & & & \\
\hline & Cr.S.Dn & 0.274 & 0.013 & 0.011 & 0.206 & 0.242 & & & & & \\
\hline \multirow{7}{*}{$\begin{array}{c}\text { Fracture } \\
\text { Stress }\end{array}$} & Age & 0.135 & 0.002 & 0.002 & 0.161 & 0.364 & 0.867 & 0.003 & 0.002 & 0.257 & 0,143 \\
\hline & BMI & 0.268 & 0.0002 & 0.0028 & 0.015 & 0.932 & & & & & \\
\hline & TMD & 0.934 & -0.001 & 0.0005 & -0.261 & 0.136 & & -0.001 & 0.0004 & & 0.082 \\
\hline & ES/BS & 0.315 & -0.004 & 0.003 & -0.219 & 0.213 & & -0.006 & 0.003 & & 0.061 \\
\hline & Cr.Le & 0.247 & 0.117 & 0.075 & 0.266 & 0.128 & & 0.113 & 0.073 & & 0.131 \\
\hline & Cr.Dn & 0.284 & -0.003 & 0.006 & -0.075 & 0.673 & & & & & \\
\hline & Cr.S.Dn & 0.261 & 0.011 & 0.010 & 0.183 & 0.301 & & & & & \\
\hline \multirow{7}{*}{$\begin{array}{l}\text { Work } \\
\text { to Failure }\end{array}$} & Age & 0.261 & -0.002 & 0.001 & -0.257 & 0.143 & & & & & \\
\hline & BMI & -0.004 & 0.005 & 0.002 & 0.507 & 0.002 & -0.004 & 0.005 & 0.002 & 0.257 & 0.002 \\
\hline & TMD & -0.184 & 0.0003 & 0.0003 & 0.178 & 0.313 & & & & & \\
\hline & ES/BS & 0.134 & -0.002 & 0.002 & -0.158 & 0.372 & & & & & \\
\hline & Cr.Le & 0.114 & 0.004 & 0.052 & 0.013 & 0.941 & & & & & \\
\hline & Cr.Dn & 0.135 & -0.005 & 0.004 & -0.214 & 0.225 & & & & & \\
\hline & Cr.S.Dn & 0.120 & -0.005 & 0.007 & -0.116 & 0.512 & & & & & \\
\hline \multirow{7}{*}{ Toughness } & Age & 120.429 & -0.666 & 0.537 & -0.214 & 0.224 & & & & & \\
\hline & BMI & 26.856 & 1.773 & 0.767 & 0.378 & 0.027 & 300.533 & 2.533 & 0.742 & 0.364 & 0.019 \\
\hline & TMD & 119.690 & -0.058 & 0.141 & -0.072 & 0.686 & & -0.288 & 0.130 & & 0.034 \\
\hline & $\mathrm{ES} / \mathrm{BS}$ & 83.365 & -1.743 & 0.942 & -0.311 & 0.074 & & -2.412 & 0.849 & & 0.008 \\
\hline & Cr.Le & 63.071 & 13.737 & 22.813 & 0.106 & 0.551 & & & & & \\
\hline & Cr.Dn & 70.691 & -1.054 & 1.764 & -0.105 & 0.554 & & & & & \\
\hline & Cr.S.Dn & 65.528 & 0.604 & 3.101 & 0.034 & 0.847 & & & & & \\
\hline
\end{tabular}

Example of a regression formula and its interpretation emerging from multivariate regression analysis for Young's Modulus:

Young's Modulus $=2.062-0.051 \times$ BMI $+0.960 \times$ Cr.Le $\rightarrow$ With each unit of BMI the Young's Modulus decreases by 0.051 units. With each unit of Cr.Le the Young's Modulus increases by 0.960 units.

BV $p=0.799 ;$ OS/BS $p=0.937$; Fig. 2). However, the resorption parameters $(\mathrm{ES} / \mathrm{BS})$ provided strong evidence of the alendronate treatment as resorption cavities were significantly lower in alendronate-treated patients (Fig. 2; $p<0.001$ ). Also, the L5 vertebrae's degree of mineralisation (TMD) increased with alendronate therapy $(p=0.037)$ and body mass index (TMD, $r=0.478$; $p=0.004$ ) (Fig. 3); however, the mineralisation parameters were not significantly different between the mid- and longterm alendronate-treated groups $(p=0.668)$.

\section{Microdamage quantification}

The crack density (i.e., the amount of microdamage per $\mathrm{mm}$ bone area) was not different between the control and 
a

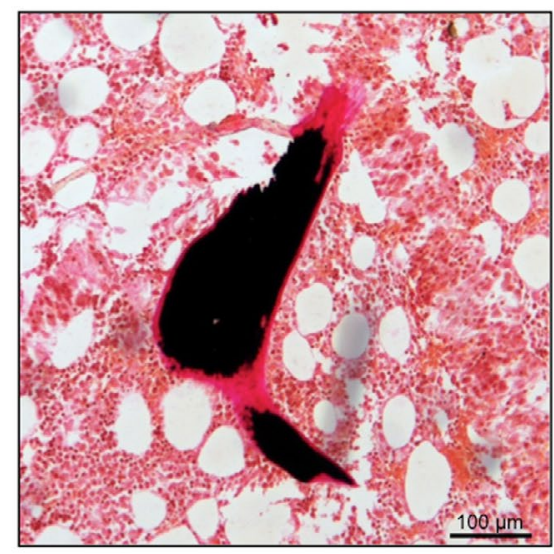

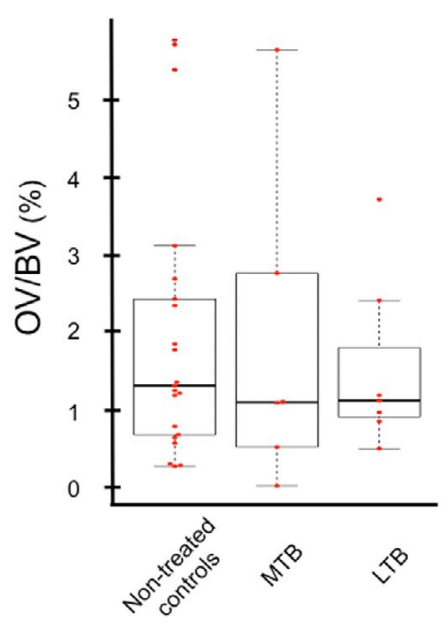

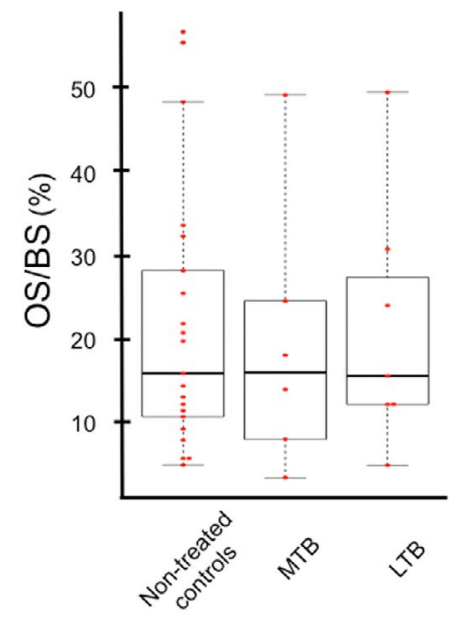

b

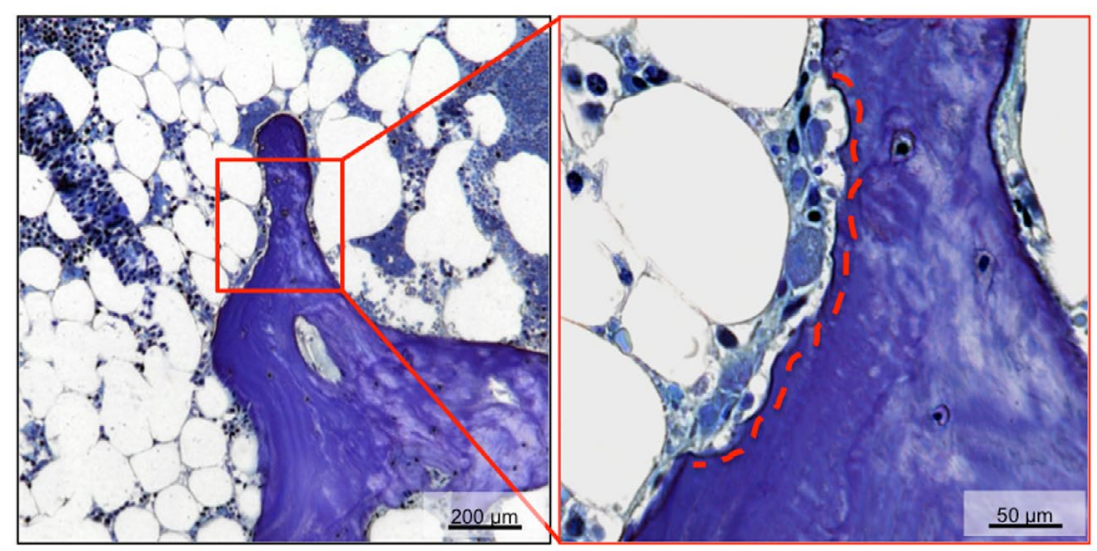

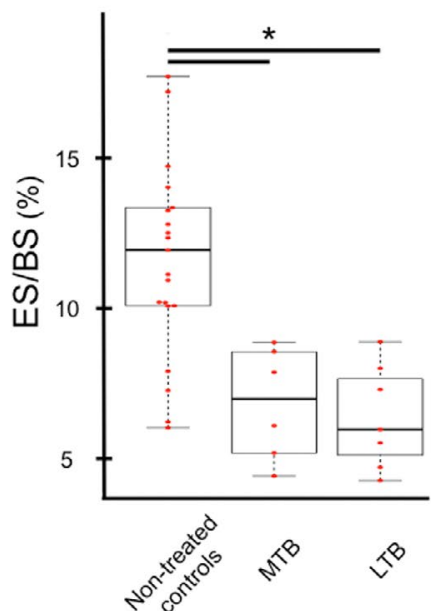

Fig. 2. (A, B) Histological analysis of undecalcified sections of L5. (A) Non-mineralised bone matrix (red) can be observed near the mineralised bone tissue (black, von Kossa staining). Osteoid volume (OV/BV) and osteoid surface $(\mathrm{OS} / \mathrm{BS})$ had a tendency to be lowest in long-term alendronate-treated patients. (B) Evidence of resorption activity in cancellous bone tissue (toluidine blue). Resorption cavities (dotted line) are considered stress raisers for single trabecular fractures. Eroded Surface (ES/BS) was lowest in alendronate-treated patients $(p<0.001)$. Comparisons were performed by $t$-test and ANOVA or the non-parametric Mann-Whitney U test and Kruskal-Wallis test.

alendronate-treated groups regardless of treatment duration $(p=0.112)$. The mean crack length had a tendency to be smallest in the long-term alendronate-treated group in comparison to the mid-term alendronate-treated group and controls $(p=0.076)$. Hence, crack surface density tended to be lower with long-term alendronate therapy in comparison with both the mid-term alendronate-treated group and controls ( $p=0.080$; Fig. 4$)$.

\section{Mechanical testing of single trabeculae}

The Young's modulus, yield strength, ultimate stress, fracture stress, work to failure and toughness did not differ significantly among the three groups (Fig. 1).

\section{Mechanical testing of single trabeculae - univariate analysis}

In a univariate analysis blind to treatment group, potential influencing confounders such as age, eroded surface or microdamage parameters were not significantly associated with mechanical parameters (Table 2). TMD was the only univariate predictor of yield strength but demonstrated just a marginal negative association (coefficient -0.001 , $p=0.036)$. Also, Young's modulus decreased with increasing degree of mineralisation as assessed by $\mu \mathrm{CT}$ (TMD coefficient $-0.007, p=0.028$ ). In addition, another independent predictor of Young's modulus was body mass index demonstrating a negative association (coefficient $-0.042, p=0.026$ ). However, increasing body mass index resulted in a higher work to failure of the tested trabeculae, which was not associated with another influencing parameter (coefficient $0.005, p=0.002$ ). Also, a higher body mass index of osteoporotic patients was associated with a higher ability to absorb energy prior to material failure in single trabeculae (toughness: coefficient 1.773, $p=0.027)$. Interestingly, TMD showed no independent association with either work to failure or toughness. Ultimate stress and fracture stress showed no association with any potentially influencing confounder (Table 2).

\section{Mechanical testing of single trabeculae - multivariate analysis}

Bone and patient characteristics are interdependent and influence each other. Hence, mechanical properties might be influenced by a combination of bone and 

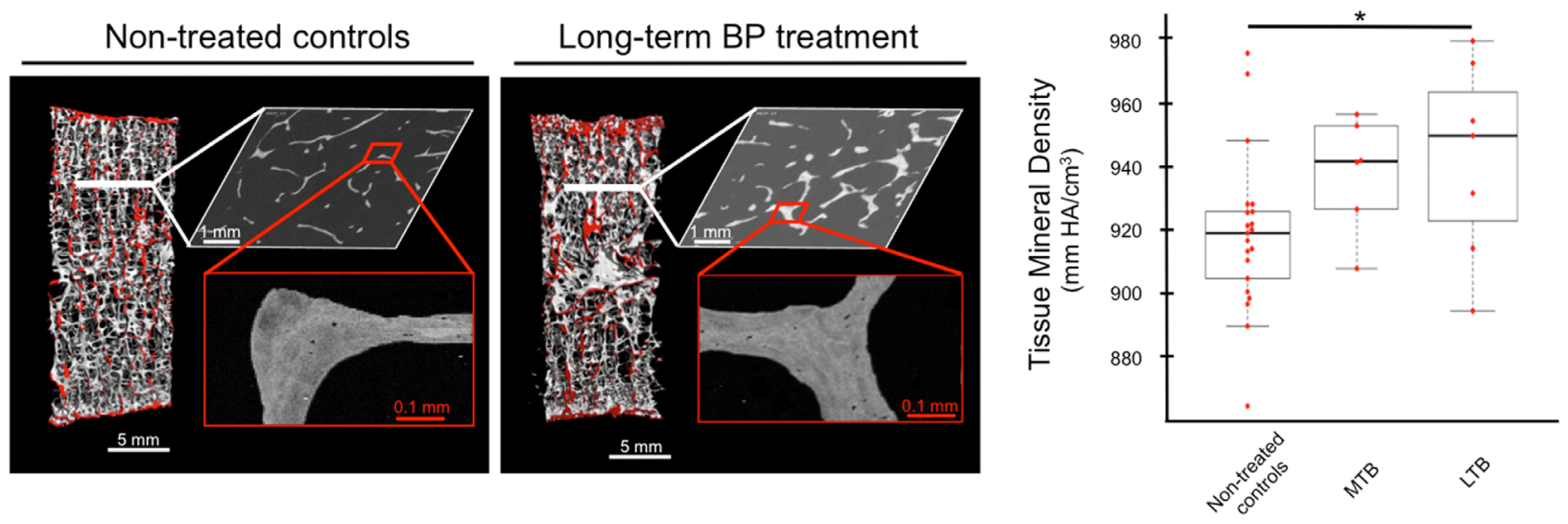

Fig. 3. Bone mineralisation assessment using $\mu \mathrm{CT}$. Tissue mineral density of a non-treated osteoporotic control case demonstrating low mineralisation and of a long-term alendronate-treated case demonstrating higher mineralisation at higher magnification (scanning electron microscopy for demonstration). TMD was higher in both mid- and longterm alendronate-treated patients compared to non-treated osteoporotic controls $(p=0.037)$. Comparisons were performed by $t$-test and ANOVA.

a

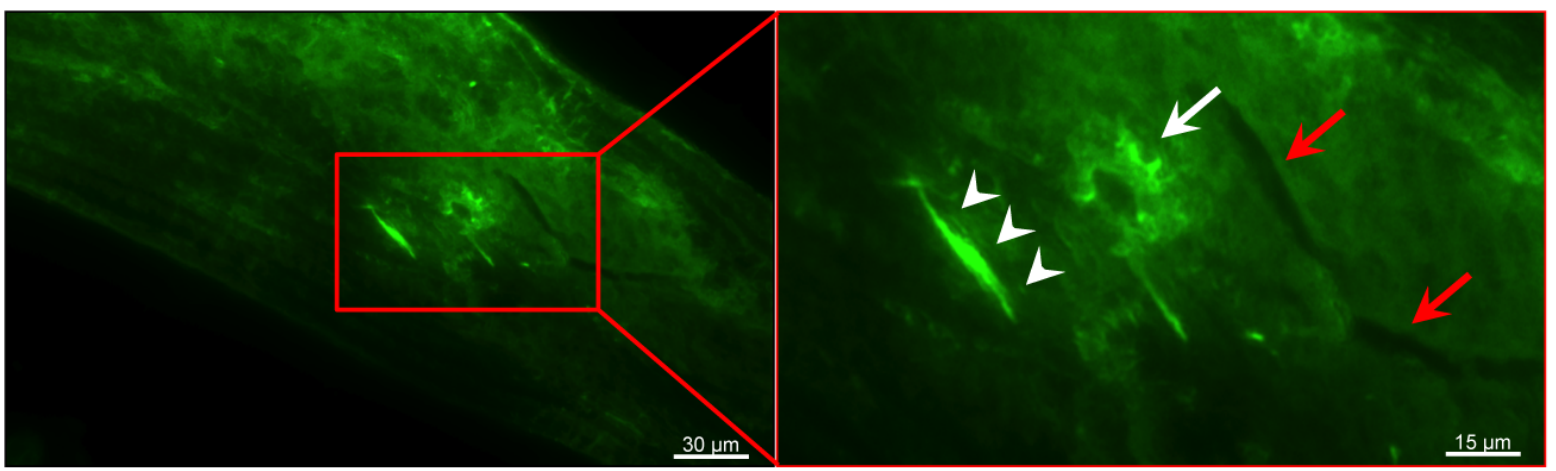

b
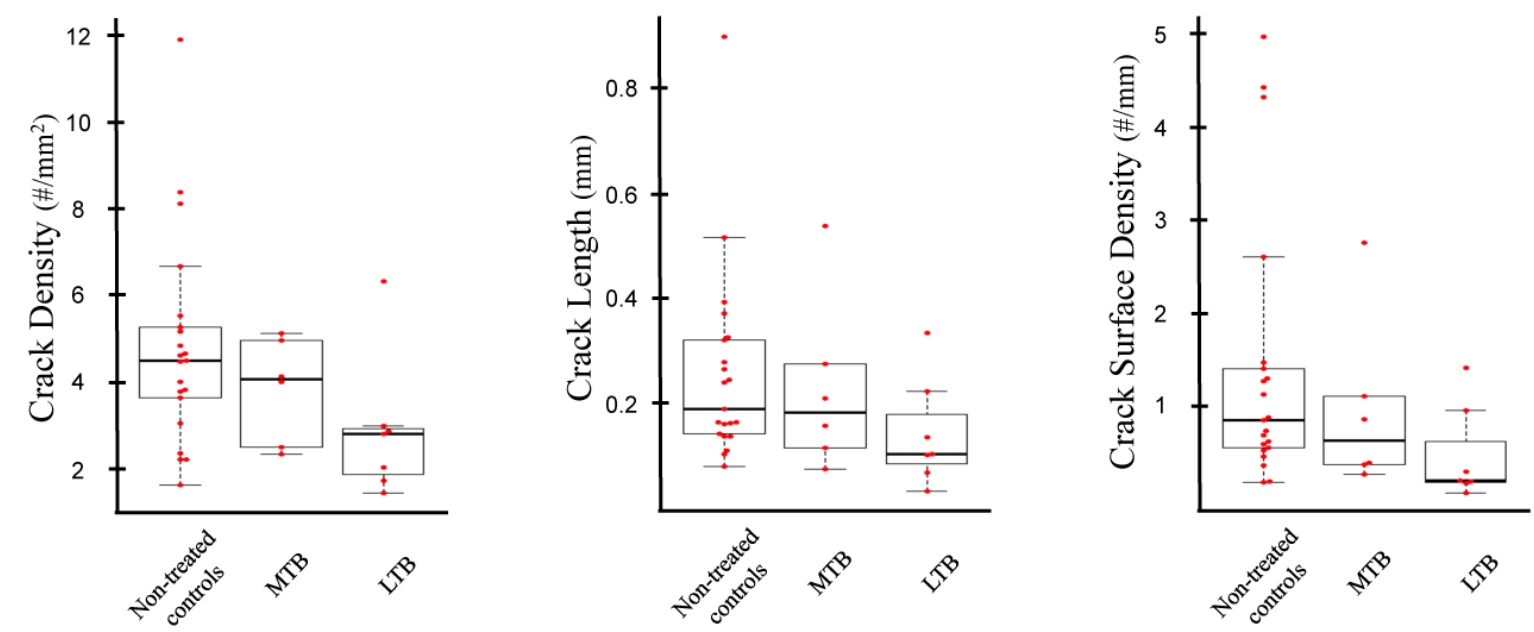

Fig. 4. (A, B) Microdamage assessment of cancellous bone. (A) Overview of single trabeculae with microdamage (calcein bulk stain). The white arrowheads indicate microdamage next to an osteocyte (white arrow) and the red arrows point to preparation artifacts. (B) Microdamage parameters have a tendency to be lower in patients with longterm alendronate treatment compared to non-treated osteoporotic controls and mid-term alendronate-treated patients but did not reach statistical significance. Comparisons were performed by $t$-test and ANOVA or the non-parametric Mann-Whitney U test and Kruskal-Wallis test. 
patient predictors with an individually different impact. Thus, an additional multivariate analysis was performed including age, body mass index, TMD, eroded surface and microdamage indices. In a subsequent search for the best subset of influencing variables, the right-hand column of Table 2 shows the results of the multivariate analysis. Compared to the univariate analysis Young's modulus still decreased with increasing body mass index. However, considering all potentially influencing parameters tested this association was highest just in combination with increasing crack length (Cr.Le) resulting in a higher Young's modulus $\left(\mathrm{R}^{2}=0.238\right)$. Furthermore, yield strength, ultimate stress and fracture stress correlated with increasing age and greater crack length in combination with a lower degree of mineralisation and eroded surface. However, work to failure was only associated with body mass index, while toughness was associated with higher body mass index, higher TMD, but most importantly a lower eroded surface representing potential stress raiser in a single trabeculae (Table 2).

\section{Discussion}

Bisphosphonates act by suppressing bone turnover; hence, a major concern is that this mechanism of preserving bone quantity in disease such as osteoporosis negatively affects the tissue characteristics leading to an accumulation of microdamage, higher mineralisation profiles and in turn deteriorated mechanical properties. Suppression of bone turnover is of particular concern for longterm bisphosphonate-treatment plans due to the recent unexplained occurrence of atypical femoral fractures in some patients (Shane et al., 2010; Donnelly et al., 2012). Indeed, in vivo failure occurs through deformation and fracture of the entire vertebral body, and will depend on a multitude of factors including the bone quantity (i.e., BV/ $\mathrm{TV}$ ) and bone quality (e.g., architecture, composition, damage, mechanical properties) at multiple length-scales. In the present study, we analyse the quality of the bone tissue at the trabecular level in patients with long-term alendronate treatment, mid-term alendronate treatment and non-treated controls with osteoporosis to determine whether alendronate treatment affects microdamage accumulation, tissue mineralisation and mechanical properties at the single trabeculae level.

One of the main effects of alendronate treatment is attributed to the suppressed rate of remodelling. Here, alendronate-treated patients demonstrated a significantly elevated degree of mineralisation than non-treated controls in vertebral bone. However, the mineralisation profile was not significantly different between the long-term and midterm alendronate treatments, which is in line with previous findings from other skeletal regions (Roschger et al., 2010; Black et al., 2012).

Along with a shift to higher mineralisation, microdamage has been observed to accumulate with bisphosphonate treatment in many pre-clinical studies (Mashiba et al., 2000; Mashiba et al., 2001; Allen et al., 2006). Clearly, the accumulation of microdamage is a concern because bisphosphonates act by suppressing bone turnover, which would reduce the number of remodelling events. However, here, an accumulation of microdamage was not found in the alendronate-treated patients. Long-term alendronatetreated patients even showed a tendency towards a lower amount of microdamage compared to non-treated controls. A similar study on iliac crest biopsies also found no association between bisphosphonate treatment duration and microdamage accumulation in humans (Chapurlat et al., 2007). Microdamage should accumulate in regions with higher mineralisation in comparison to the surrounding tissue (Wasserman et al., 2005). Given that Roschger et al. (Roschger et al., 2010) did not observe a higher incidence of abnormal highly mineralised bone areas after long-term bisphosphonate treatment in biopsies of human iliac crest bone, the lack of microdamage accumulation observed here in vertebral bodies is conceivable.

In accordance with the occurrence of microdamage, we were unable to find differences in the mechanical parameters of single trabeculae from alendronate-treated patients and non-treated osteoporotic controls. The mechanical properties of the single trabeculae here contrast with previous studies (computational and experimental in nature) using whole vertebral bodies that have found a higher vertebral compressive strength with bisphosphonate treatment (Mashiba et al., 2001; Keaveny et al., 2007). When testing whole vertebral bodies, the cortical thickness and trabecular architecture affect the mechanical properties. In addition to strength, toughness is another important material property in relation to bone quality (Launey and Ritchie, 2009) and defines the ability to absorb energy in the process before material failure. In cases where bone turnover is affected, such as osteoporosis and the treatment of osteoporosis, bone strength and toughness can become impaired (Busse et al., 2009). Despite the potential of bisphosphonates to reduce the occurrence of vertebral and non-vertebral fractures, preclinical animal studies have suggested that bisphosphonate treatments are associated with a reduced toughness (Mashiba et al., 2000; Mashiba et al., 2001; Komatsubara et al., 2003; Allen and Burr, 2007). However, in the present study, the mid-term and long-term alendronate treatments did not result in a reduced toughness of single lumbar trabeculae in comparison to untreated osteoporotic controls.

Therefore, even though the mid- and long-term alendronate treatments had a slightly higher mineralisation, there was no change in mechanical properties or microdamage accumulation in comparison to non-treated osteoporotic bone. While the larger-scale vertebral features (such as cortical shell, trabecular architecture) may contribute to fracture risk reduction, the data presented here demonstrate that histologically the alendronate-treated bone and osteoporotic controls are different through the higher mineralisation profile and a smaller eroded surface, which are both established effects of the suppression of turnover induced by alendronate (Balena et al., 1993). Thus, we theorise that even though the alendronate-treated individuals have a higher TMD, which should decrease their toughness, the reduction in resorption cavities may counteract the TMD to maintain the bone toughness after alendronate treatment. Indeed, in past studies, resorption cavities were identified to predict fracture risk independent 
of aBMD because they decrease the overall bone area and may be considered as stress concentrations, where fractures can initiate (Garnero, 2000; Hernandez, 2008; Slyfield et al., 2012).

The univariate analysis between the mechanical properties and other possible predictors of fracture showed that the body mass index was associated with the mechanical properties. In clinical studies, the positive influence of the body mass index on fracture risk was primarily attributed to improved geometric strength and higher aBMD levels most probably due to adaptation to increased loading conditions (Beck et al., 2001; Beck et al., 2009). This was supported by our results as body mass index positively correlated with mineralisation data. However, the degree of mineralisation was not associated with toughness in the univariate analysis suggesting that body mass index has additional effects on bone material characteristics. As many of the bone characteristics are interrelated, the mechanical properties may be related to a joint contribution from multiple predictors. Thus, an additional multivariate analysis was performed. Here, toughness was influenced by a combination of TMD, body mass index and eroded surface. As discussed above, body mass index is commonly associated with improved geometric strength and higher aBMD levels (Beck et al., 2001; Beck et al., 2009) as well as TMD, in this study. Therefore, the multivariate analysis reflects the fact that combined changes in mineral density (through TMD or body mass index) and eroded surface influence the mechanical properties.

This study has some limitations. First, due to the retrospective study design, follow-up measurements were not possible, and there was no knowledge of the starting values for the parameters measured, which needs to be taken into account when looking at the restricted number of patients. However, the BioAsset study allowed a unique recruitment of patients with mid- and long-term alendronate treatments. The mechanical tests on single trabeculae from vertebral bodies also pose a few limitations. While testing material in its fresh state is optimal, special sample preparation techniques are required to singularise the trabeculae. In particular, the effect of hydrogen peroxide treatment to remove soft tissue is controversial; however, there is no strong evidence that the short hydrogen peroxide treatment affects the collagen or mineral properties due to the preservation of the collagenous matrix (osteoid) (Chng et al., 2005; DePaula et al., 2005; Joiner, 2007; Busse et al., 2009; Li et al., 2011). Second, specimens were also tested dry, which could influence the mechanical properties. Dry testing particularly influences the strength and toughness by reducing the plasticity generated in the sample through deformation of the organic components. However, as all groups were tested in a dry state, a comparison is valid. Third, the materials properties and geometry could change throughout the cross-section of the trabeculae, which would pose another limitation to precisely measuring mechanical properties, but this mechanical testing technique has been implemented numerous times to investigate this small but important feature within the cancellous bone structure (Carretta et al., 2013; Ridha and Thurner, 2013). Fourth, an additional contribution to the trabecular mechanical properties would be the inorganic component of bone. Indeed, increased levels of cross-linking within the organic component have been associated with fragility fractures (Saito et al., 2006), as the cross-links presumably restrict deformation at small length-scales within bone (Zimmermann et al., 2011). However, previous studies present in the literature do conflict over the effects of bisphosphonate treatment on the cross-linking profile within bone (Allen et al., 2008; Boskey et al., 2009; Gourion-Arsiquaud et al., 2010; Donnelly et al., 2012). Nonetheless, a drawback to the present study is that this level of the bone structure was not analysed.

In summary, here, we characterise the structure and mechanical properties of individual trabeculae from patients with long-term alendronate treatment, mid-term alendronate treatment and osteoporotic controls. From strength tests on single trabeculae, no differences were found between the alendronate-treated groups and the osteoporotic controls. The alendronate treatments did result in an elevated mineralisation profile in cancellous vertebral bone, which is a hallmark of bone turnover suppression due to treatment. However, the higher mineralisation profile's impact on the mechanical properties may be compensated by fewer resorption cavities (i.e., more bone is present or potential stress raisers are eliminated) in the alendronatetreated bone. This counterbalance was supported by a multivariate analysis showing that multiple factors, such as body mass index, bone mineralisation and eroded surface, can together influence the trabeculae's mechanical properties.

\section{Acknowledgements}

This project was supported by the German Federal Ministry of Education and Research by the grant 'BMBF, BioAsset 01EC1005D' to MA, KP, MMM and CCG and by the grant 'BMBF, Osteopath $01 \mathrm{EC} 1006$ ' to MA. BB is a fellow of the DFG - Emmy Noether program (Deutsche Forschungsgemeinschaft - German Research Foundation; BU 2562/2-1).

\section{References}

Allen MR, Burr DB (2007) Three years of alendronate treatment results in similar levels of vertebral microdamage as after one year of treatment. J Bone Miner Res 22: 17591765.

Allen MR, Burr DB (2011) Bisphosphonate effects on bone turnover, microdamage, and mechanical properties: what we think we know and what we know that we don't know. Bone 49: 56-65.

Allen MR, Iwata K, Sato M, Burr DB (2006) Raloxifene enhances vertebral mechanical properties independent of bone density. Bone, 39:1130-1135.

Allen MR, Gineyts E, Leeming DJ, Burr DB, Delmas PD (2008) Bisphosphonates alter trabecular bone collagen cross-linking and isomerization in beagle dog vertebra. Osteoporosis Int 19: 329-337.

Ammann P, Rizzoli R (2003) Bone strength and its determinants. Osteoporosis Int 14 Suppl 3: S13-18. 
Aruwajoye OO, Patel MK, Allen MR, Burr DB, Aswath PB, Kim HK (2013) Microcrack density and nanomechanical properties in the subchondral region of the immature piglet femoral head following ischemic osteonecrosis. Bone 52: 632-639.

Bala Y, Farlay D, Chapurlat RD, Boivin G (2011) Modifications of bone material properties in postmenopausal osteoporotic women long-term treated with alendronate. Eur J Endocrinol 165: 647-655.

Balena R, Toolan BC, Shea M, Markatos A, Myers ER, Lee SC, Opas EE, Seedor JG, Klein H, Frankenfield D, Quartuccio H, Fioravanti C, Clair J, Brown E, Hayes WC, Rodan GA (1993) The effects of 2-year treatment with the aminobisphosphonate alendronate on bone metabolism, bone histomorphometry, and bone strength in ovariectomized nonhuman primates. J Clin Invest 92: 2577-2586.

Beck TJ, Oreskovic TL, Stone KL, Ruff CB, Ensrud K, Nevitt MC, Genant HK, Cummings SR (2001) Structural adaptation to changing skeletal load in the progression toward hip fragility: the study of osteoporotic fractures. J Bone Miner Res 16: 1108-1119.

Beck TJ, Petit MA, Wu G, LeBoff MS, Cauley JA, Chen Z (2009) Does obesity really make the femur stronger? BMD, geometry, and fracture incidence in the women's health initiative-observational study. J Bone Miner Res 24: 1369-1379.

Black DM, Cummings SR, Karpf DB, Cauley JA, Thompson DE, Nevitt MC, Bauer DC, Genant HK, Haskell WL, Marcus R, Ott SM, Torner JC, Quandt SA, Reiss TF, Ensrud KE. (1996) Randomised trial of effect of alendronate on risk of fracture in women with existing vertebral fractures. Fracture Intervention Trial Research Group. Lancet 348: 1535-1541.

Black DM, Schwartz AV, Ensrud KE, Cauley JA, Levis S, Quandt SA, Satterfield S, Wallace RB, Bauer DC, Palermo L, Wehren LE, Lombardi A, Santora AC, Cummings SR; FLEX Research Group (2006) Effects of continuing or stopping alendronate after 5 years of treatment: the Fracture Intervention Trial Long-term Extension (FLEX): a randomized trial. JAMA 296: $2927-$ 2938.

Black DM, Reid IR, Boonen S, Bucci-Rechtweg C, Cauley JA, Cosman F, Cummings SR, Hue TF, Lippuner K, Lakatos P, Leung PC, Man Z, Martinez RL, Tan M, Ruzycky ME, Su G, Eastell R (2012) The effect of 3 versus 6 years of zoledronic acid treatment of osteoporosis: a randomized extension to the HORIZON-Pivotal Fracture Trial (PFT). J Bone Miner Res 27: 243-254.

Boivin GY, Chavassieux PM, Santora AC, Yates J, Meunier PJ (2000) Alendronate increases bone strength by increasing the mean degree of mineralization of bone tissue in osteoporotic women. Bone 27: 687-694.

Bone HG, Hosking D, Devogelaer JP, Tucci JR, Emkey RD, Tonino RP, Rodriguez-Portales JA, Downs RW, Gupta J, Santora AC, Liberman UA; Alendronate Phase III Osteoporosis Treatment Study Group (2004) Ten years' experience with alendronate for osteoporosis in postmenopausal women. N Engl J Med 350: 1189-1199.

Boskey AL, Spevak L, Weinstein RS (2009) Spectroscopic markers of bone quality in alendronate- treated postmenopausal women. Osteoporosis Int 20: 793-800.

Bottai V, Giannotti S, Dell'osso G, De Paola G, Menconi A, Falossi F, Raffaetà G, Guido G (2014) Atypical femoral fractures: retrospective radiological study of 319 femoral fractures and presentation of clinical cases. Osteoporosis Int 25: 993-997.

Breer S, Krause M, Busse B, Hahn M, Rüther W, Morlock MM, Amling M, Zustin J (2012) Analysis of retrieved hip resurfacing arthroplasties reveals the interrelationship between interface hyperosteoidosis and demineralization of viable bone trabeculae. J Orthop Res 30: 1155-1161.

Burghardt AJ, Kazakia GJ, Laib A, Majumdar S (2008) Quantitative assessment of bone tissue mineralization with polychromatic micro-computed tomography. Calcif Tissue Int 83: 129-138.

Burr DB, Stafford T (1990) Validity of the bulkstaining technique to separate artifactual from in vivo bone microdamage. Clin Orthop Rel Res 260: 305-308.

Busse B, Hahn M, Soltau M, Zustin J, Püschel K, Duda GN, Amling M (2009) Increased calcium content and inhomogeneity of mineralization render bone toughness in osteoporosis: mineralization, morphology and biomechanics of human single trabeculae. Bone 45: 1034-1043.

Carretta R, Luisier B, Bernoulli D, Stussi E, Muller R, Lorenzetti S (2013) Novel method to analyze post-yield mechanical properties at trabecular bone tissue level. $\mathrm{J}$ Mech Behav Biomed Mater 20: 6-18.

Chapurlat RD, Arlot M, Burt-Pichat B, Chavassieux P, Roux JP, Portero-Muzy N, Delmas PD (2007) Microcrack frequency and bone remodeling in postmenopausal osteoporotic women on long-term bisphosphonates: a bone biopsy study. J Bone Miner Res 22: 1502-1509.

Chng HK, Ramli HN, Yap AU, Lim CT (2005) Effect of hydrogen peroxide on intertubular dentine. J Dent 33: 363-369.

Cummings SR, Black DM, Thompson DE, Applegate WB, Barrett-Connor E, Musliner TA, Palermo L, Prineas R, Rubin SM, Scott JC, Vogt T, Wallace R, Yates AJ, LaCroix AZ (1998) Effect of alendronate on risk of fracture in women with low bone density but without vertebral fractures: results from the Fracture Intervention Trial. JAMA 280: 2077-2082.

Day JS, Ding M, Bednarz P, van der Linden JC, Mashiba T, Hirano T, Johnston CC, Burr DB, Hvid I, Sumner DR, Weinans H (2004) Bisphosphonate treatment affects trabecular bone apparent modulus through microarchitecture rather than matrix properties. J Orthop Res 22: 465-471.

Dempster DW, Compston JE, Drezner MK, Glorieux FH, Kanis JA, Malluche H, Meunier PJ, Ott SM, Recker RR, Parfitt AM (2013) Standardized nomenclature, symbols, and units for bone histomorphometry: a 2012 update of the report of the ASBMR Histomorphometry Nomenclature Committee. J Bone Miner Res 28: 2-17.

DePaula CA, Truncale KG, Gertzman AA, Sunwoo MH, Dunn MG (2005) Effects of hydrogen peroxide cleaning procedures on bone graft osteoinductivity and mechanical properties. Cell Tissue Bank 6: 287-298. 
Ding M, Day JS, Burr DB, Mashiba T, Hirano T, Weinans H, Sumner DR, Hvid I (2003) Canine cancellous bone microarchitecture after one year of high-dose bisphosphonates. Calcified tissue international, 72:737744.

Donnelly E, Meredith DS, Nguyen JT, Gladnick BP, Rebolledo BJ, Shaffer AD, Lorich DG, Lane JM, Boskey AL (2012) Reduced cortical bone compositional heterogeneity with bisphosphonate treatment in postmenopausal women with intertrochanteric and subtrochanteric fractures. J Bone Miner Res 27: 672-678.

Garnero P (2000) Markers of bone turnover for the prediction of fracture risk. Osteoporosis Int 1 Suppl 6: S55-65.

Glüer C-C, Krause M, Museyko O, Wulff B, Campbell G, Damm T, Daugschies M, Huber G, Lu Y, Peña J, Waldhausen S, Bastgen J, Rohde K, Breer S, Steinebach I, Thomsen F, Amling M, Barkmann R, Engelke K, Morlock M, Pfeilschifter J, Püschel K (2013) New horizons for the in vivo assessment of major aspects of bone quality. Microstructure and material properties assessed by quantitative computed tomography and quantitative ultrasound methods developed by the BioAsset consortium. Osteology 22: 223-233.

Gourion-Arsiquaud S, Allen MR, Burr DB, Vashishth D, Tang SY, Boskey AL (2010) Bisphosphonate treatment modifies canine bone mineral and matrix properties and their heterogeneity. Bone 46: 666-672.

Guerri-Fernandez RC, Nogues X, Torres Del Pliego E, Puig L, García-Giralt N, Yoskovitz G, Mellibovsky L, Hansma PK, Díez-Pérez A (2013) Microindentation for in vivo measurement of bone tissue material properties in atypical femoral fracture patients and controls. J Bone Miner Res 28: 162-168.

Harris ST, Watts NB, Genant HK, McKeever CD, Hangartner T, Keller M, Chesnut CH 3rd, Brown J, Eriksen EF, Hoseyni MS, Axelrod DW, Miller PD (1999) Effects of risedronate treatment on vertebral and nonvertebral fractures in women with postmenopausal osteoporosis: a randomized controlled trial. Vertebral Efficacy With Risedronate Therapy (VERT) Study Group. JAMA 282: 1344-1352.

Hernandez CJ (2008) How can bone turnover modify bone strength independent of bone mass? Bone 42: 10141020 .

Joiner A (2007) Review of the effects of peroxide on enamel and dentine properties. J Dent 35: 889-896.

Keaveny TM, Donley DW, Hoffmann PF, Mitlak BH, Glass EV, San Martin JA (2007) Effects of teriparatide and alendronate on vertebral strength as assessed by finite element modeling of QCT scans in women with osteoporosis. J Bone Miner Res 22: 149-157.

Komatsubara S, Mori S, Mashiba T, Li J, Nonaka K, Kaji Y, Akiyama T, Miyamoto K, Cao Y, Kawanishi J, Norimatsu H (2003) Long-term treatment of incadronate disodium accumulates microdamage but improves the trabecular bone microarchitecture in dog vertebra. J Bone Miner Res 18: 512-520.

Krause M, Breer S, Hahn M, Rüther W, Morlock MM, Amling M, Zustin J (2012a) Cementation and interface analysis of early failure cases after hip-resurfacing arthroplasty. Int Orthop 36: 1333-1340.

Krause M, Breer S, Mohrmann B, Vettorazzi E, Marshall RP, Amling M, Barvencik F (2012b) Influence of non-traumatic thoracic and lumbar vertebral fractures on sagittal spine alignment assessed by radiation-free spinometry. Osteoporosis Int 24: 1859-1868.

Krause M, Museyko O, Breer S, Wulff B, Duckstein C, Vettorazzi E, Glueer C, Püschel K, Engelke K, Amling M (2014) Accuracy of trabecular structure by HR-pQCT compared to gold standard muCT in the radius and tibia of patients with osteoporosis and long-term bisphosphonate therapy. Osteoporosis Int $25: 1595-1606$.

Launey ME, Ritchie RO (2009) On the fracture toughness of advanced materials. Adv Mater 21: 21032110 .

Lee TC, Arthur TL, Gibson LJ, Hayes WC (2000) Sequential labelling of microdamage in bone using chelating agents. J Orthopaed Res 18: 322-325.

Lee TC, Mohsin S, Taylor D, Parkesh R, Gunnlaugsson T, O’Brien FJ, Giehl M, Gowin W (2003) Detecting microdamage in bone. J Anat 203: 161-172.

Li D, Bi L, Meng G, Wang J, Lv R, Liu M, Liu J, Hu Y (2011) Mineral status and mechanical properties of cancellous bone exposed to hydrogen peroxide for various time periods. Cell Tissue Bank 12: 51-58.

Mashiba T, Hirano T, Turner CH, Forwood MR, Johnston CC, Burr DB (2000) Suppressed bone turnover by bisphosphonates increases microdamage accumulation and reduces some biomechanical properties in dog rib.J Bone Miner Res 15: 613-620.

Mashiba T, Turner CH, Hirano T, Forwood MR, Johnston CC, Burr DB (2001) Effects of suppressed bone turnover by bisphosphonates on microdamage accumulation and biomechanical properties in clinically relevant skeletal sites in beagles. Bone 28: 524-531.

Mulder L, Koolstra JH, Van Eijden TM (2004) Accuracy of microCT in the quantitative determination of the degree and distribution of mineralization in developing bone. Acta Radiol 45: 769-777.

Museyko O, Heinemann A, Krause M, Wulff B, Amling M, Püschel K, Glüer CC, Kalender W, Engelke K (2014) A low-radiation exposure protocol for 3D QCT of the spine. Osteoporosis Int 25: 983-992.

Nyman JS, Yeh OC, Hazelwood SJ, Martin RB (2004) A theoretical analysis of long-term bisphosphonate effects on trabecular bone volume and microdamage. Bone 35: 296-305.

Oleksik A, Lips P, Dawson A, Minshall ME, Shen W, Cooper C, Kanis J (2000) Health-related quality of life in postmenopausal women with low BMD with or without prevalent vertebral fractures. J Bone Miner Res 15: 13841392.

Ridha H, Thurner PJ (2013) Finite element prediction with experimental validation of damage distribution in single trabeculae during three-point bending tests. J Mech Behav Biomed Mater 27: 94-106.

Roschger P, Rinnerthaler S, Yates J, Rodan GA, Fratzl P, Klaushofer K (2001) Alendronate increases degree and uniformity of mineralization in cancellous bone and 
decreases the porosity in cortical bone of osteoporotic women. Bone 29: 185-191.

Roschger P, Lombardi A, Misof BM, Maier G, FratzlZelman N, Fratzl P, Klaushofer K (2010) Mineralization density distribution of postmenopausal osteoporotic bone is restored to normal after long-term alendronate treatment: qBEI and sSAXS data from the fracture intervention trial long-term extension (FLEX). J Bone Miner Res 25: 48-55.

Saito M, Fujii K, Soshi S, Tanaka T (2006) Reductions in degree of mineralization and enzymatic collagen crosslinks and increases in glycation-induced pentosidine in the femoral neck cortex in cases of femoral neck fracture. Osteoporosis Int 17: 986-995.

Shane E, Burr D, Ebeling PR, Adler RA, Brown TD, Cheung AM, Cosman F, Curtis JR, Dell R, Dempster DW, Ebeling PR, Einhorn TA, Genant HK, Geusens P, Klaushofer K, Lane JM, McKiernan F, McKinney R, Ng A, Nieves J, O'Keefe R, Papapoulos S, Howe TS, van der Meulen MC, Weinstein RS, Whyte MP (2010) Atypical subtrochanteric and diaphyseal femoral fractures: report of a task force of the American Society for Bone and Mineral Research. J Bone Miner Res 25: 2267-2294.

Slyfield CR, Tkachenko EV, Fischer SE, Ehlert KM, Yi IH, Jekir MG, O’Brien RG, Keaveny TM, Hernandez CJ (2012) Mechanical failure begins preferentially near resorption cavities in human vertebral cancellous bone under compression. Bone 50: 1281-1287.

Stepan JJ, Burr DB, Pavo I, Sipos A, Michalska D, Li J, Fahrleitner-Pammer A, Petto H, Westmore M, Michalsky D, Sato M, Dobnig H (2007) Low bone mineral density is associated with bone microdamage accumulation in postmenopausal women with osteoporosis. Bone 41: 378385.

Tjhia CK, Odvina CV, Rao DS, Stover SM, Wang X, Fyhrie DP (2011) Mechanical property and tissue mineral density differences among severely suppressed bone turnover (SSBT) patients, osteoporotic patients, and normal subjects. Bone 49: 1279-1289.

Vaishya R, Vaish A, Nadeem A (2013) Bisphosphonateinduced atypical subtrochanteric femoral fracture. BMJ Case Rep pii: bcr2013201931.

Wang X, Allen MR, Burr DB, Lavernia EJ, Jeremic B, Fyhrie DP (2008) Identification of material parameters based on Mohr-Coulomb failure criterion for bisphosphonate treated canine vertebral cancellous bone. Bone 43: 775780 .

Wasserman N, Yerramshetty J, Akkus O (2005) Microcracks colocalize within highly mineralized regions of cortical bone tissue. Eur J Morphol 42: 43-51.

Zanchetta MB, Diehl M, Buttazzoni M, Galich A, Silveira, Bogado CE, Zanchetta JR (2014) Assessment of bone microarchitecture in postmenopausal women on long-term bisphosphonate therapy with atypical fractures of the femur. J Bone Miner Res 29: 999-1004.

Zimmermann EA, Schaible E, Bale H, Barth HD, Tang SY, Reichert P, Busse B, Alliston T, Ager JW 3rd, Ritchie RO (2011) Age-related changes in the plasticity and toughness of human cortical bone at multiple length scales. Proc Natl Acad Sci USA 108: 14416-14421.

\section{Discussion with Reviewers}

S. Gamsjaeger: Can the results obtained in the trabecular bone of the spine transferred to other skeletal sites or is this a site-specific effect?

Authors: Previous studies have shown that the effect of bisphosphonate treatment is highly site specific (Smith et al., 2003; Allen et al, 2010, additional references). In particular, the bisphosphonate-related reduction in bone resorption has been shown to be lower at peripheral sites than at the iliac crest or the vertebral body. In addition, the effects of BP treatment seem to depend also on the surface-to-volume ratio of the bone compartment ( $\mathrm{Hu}$ et al., 2002, additional reference) and its metabolic activity (Lin, 1996; Rodan, 1998; Rogers et al., 2000, additional references). Hence, a transfer of the present results to other skeletal sites may not be appropriate.

S. Gamsjaeger: Does your study imply that the advantages of long-term bisphosphonate treatment in manifested osteoporosis, e.g., preservation of increased bone mineral density, predominate possible effects on bone mechanical properties?

Authors: Here, we do not wish to make a claim that the advantages of long-term bisphosphonates outweigh possible impacts on the mechanical properties particularly because bisphosphonates have site-specific effects on the structural characteristics and mechanical properties of bone. However, specific to trabecular bone from the lumbar spine, our data showed that a preservation of increased bone mineral density in trabeculae does not result in an increased accumulation of microdamage. In addition, the reduced osteoclastic activity found in long-term bisphosphonate cases is associated with fewer resorptive lacunae, which could act as potential stress raisers for trabecular fractures. The lesser degree of resorptive lacunae seems to counterbalance potentially adverse effects on vertebral trabecular biomechanical properties.

A. Ignatius: The argument given for the use of peroxide is rather weak. Osteoid may remain intact, but the suspected effect of peroxide involves the dissolution of small immature crystallites. Please comment.

Authors: We agree that it is always a limitation when sample preparation techniques may endanger the physical integrity of the specimens. However, as we state in the limitations of the study paragraph, the effect of peroxide is minimal. In addition, prior to the experimental investigation, pilot tests were performed with quantitative backscattered electron imaging and did not indicate any significant change in the degree of mineralisation in bone samples before or after peroxide treatment, which is further supported by recent Raman spectroscopy analyses where peroxide treatments are common (Penel et al., 2005; Petra et al., 2005, additional references).

A. Ignatius: Are the $\mu \mathrm{CT}$ and $\mathrm{qBEI}$ results as expressed, influenced by a variable $\mathrm{Ca} / \mathrm{P}$ ratio of the mineral crystallites? After all, bisphosphonates have been shown to directly affect the mineral properties through physical chemical mechanisms. 
Authors: The $\mu \mathrm{CT}$ determines bone tissue mineralisation by measuring image intensity values (X-ray linear attenuation), which reflect compositional properties of the imaged field of view (FOV). These gray-scale attenuation values were calibrated against standard mineral density values using a phantom containing hydroxyapatite cylinders. Burghardt et al. have demonstrated high reproducibility of the assessment of bone tissue mineral density (Burghardt et al., 2008, text reference). Given that non-destructive $\mu \mathrm{CT}$ is an established tool to measure the $\mathrm{TMD}$, it is commonly used to monitor treatment effects in bone diseases (Nazarian et al., 2008; Deuerling et al., 2010; Shahnazari et al., 2010; Wagner et al., 2011, additional references).

H. Zahedmanesh: The number of patients reported for the control group is three-fold higher than the number of patients with bisphosphonate treatment. The authors need to justify that this does not compromise the main findings of the study.

Authors: The imbalance in group sizes does not affect the performed statistical analyses. From our point of view, the approach is in accordance with the statistical theory of the analyses used. The fact that the control group is bigger is even beneficial for the overall power of the statistical tests.

H. Zahedmanesh: Regarding Fig. 1a, the fracture toughness and work to fracture are lower in the long-term group compared to the mid-term group, although, not statistically significant. Albeit, given the limited number of patients, this visible trend does not corroborate the core result of the article if not compromise it.

Authors: We thank the reviewer for closely analysing the trends in the data, but we believe that these trends do not reflect a clear result. The work to failure and toughness values shown in Fig. 1b do not show any significant change between the compared groups.

H. Zahedmanesh: In the authors' opinion, do the trends identified based on micromechanical tests at the trabeculae level such as fracture toughness, predict similar trends at the tissue level (vertebrae)?

Authors: We believe that micromechanical tests on single trabeculae cannot reflect the mechanical properties of whole vertebral bodies. Apart from the inherent resistance of the bone tissue, an important aspect of trabecular bone's resistance to failure is the $3 \mathrm{D}$ network of trabeculae and the cortical shell. Thus, by using single trabeculae, we are using a rather idealised test specimen (small cylindrical) that is not influenced by any structural effects due to variations in orientation of trabeculae, trajectories, influence of the cortical shell, polyostotic heterogeneity in trabecular networks. Thus, by using somewhat idealised test specimen, we can determine directly whether the composition, microdamage distribution and/or structural changes to the trabeculae due to bisphosphonate treatment influence the mechanical properties of the bone tissue, while minimising confounding factors.
D. Ruffoni: Single trabeculae are neither homogenous in material properties nor uniform in cross section. Which is the impact of these "imperfections" on the material properties derived with three-point bending at the lengthscale of single trabeculae? In addition, how large is the error on the measured elastic and failure properties? How can the authors be sure that the proposed method is accurate enough to detect possible difference in the mechanical competence of the trabeculae extracted from treated and non-treated bones?

Authors: It is correct that the inhomogeneous material properties and size of the sample could influence the mechanical property measurements. The data may have a greater statistical significance if the moment of inertia and the variation in the composition were accurately quantified prior to measurement. Unfortunately, accurate measurements of the composition and geometry would require techniques, such as $\mu \mathrm{CT}$ that would also damage the sample prior to mechanical testing. With these thoughts in mind, we acknowledge the limitations imposed by the technique in the limitations of the study paragraph. However, the testing of trabeculae in three-point bending is essential as they represent the smallest structural entity within the vertebral structure resisting load and this technique has been previously used in consideration of the limitations (Carretta et al., 2013; Ridha and Turner, 2013, text references).

\section{Additional References}

Allen MR, Kubek DJ, Burr DB (2010) Cancer treatment dosing regimens of zoledronic acid result in near-complete suppression of mandible intracortical bone remodeling in beagle dogs. J Bone Miner Res 25: 98-105.

Deuerling JM, Rudy DJ, Niebur GL, Roeder RK (2010) Improved accuracy of cortical bone mineralization measured by polychromatic microcomputed tomography using a novel high mineral density composite calibration phantom. Med Phys 37: 5138-5145.

Hu JH, Ding M, Søballe K, Bechtold JE, Danielsen CC, Day JS, Hvid I (2002) Effects of short-term alendronate treatment on the three-dimensional microstructural, physical, and mechanical properties of dog trabecular bone. Bone 31: 591-597.

Lin JH (1996) Bisphosphonates: a review of their pharmacokinetic properties. Bone 18: 75-85.

Nazarian A, Snyder BD, Zurakowski D, Müller R (2008) Quantitative micro-computed tomography: a noninvasive method to assess equivalent bone mineral density. Bone 43: 302-311.

Penel G, Delfosse C, Descamps M, Leroy G (2005) Composition of bone and apatitic biomaterials as revealed by intravital Raman microspectroscopy. Bone 36: 893-901.

Petra M, Anastassopoulou J, Theologis T, Theophanides T (2005) Synchrotron micro-FT-IR spectroscopic evaluation of normal paediatric human bone. J Mol Struct 733: 101-110. 
Rodan GA (1998) Mechanisms of action of bisphosphonates. Ann Rev Pharmacol Toxicol 38: 375-388.

Rogers MJ, Gordon S, Benford HL, Coxon FP, Luckman SP, Monkkonen J, Frith JC (2000) Cellular and molecular mechanisms of action of bisphosphonates. Cancer 88(12 Suppl): 2961-2978.

Shahnazari M, Yao W, Dai W, Wang B, Ionova-Martin SS, Ritchie RO, Heeren D, Burghardt AJ, Nicolella DP, Kimiecik MG, Lane NE (2010) Higher doses of bisphosphonates further improve bone mass, architecture, and strength but not the tissue material properties in aged rats. Bone 46: 1267-1274.

Smith SY, Recker RR, Hannan M, Müller R, Bauss F (2003) Intermittent intravenous administration of the bisphosphonate ibandronate prevents bone loss and maintains bone strength and quality in ovariectomized cynomolgus monkeys. Bone 32: 45-55.

Wagner DW, Lindsey DP, Beaupre GS (2011) Deriving tissue density and elastic modulus from microCT bone scans. Bone 49: 931-938. 